\title{
Redefiniendo el Estado: las implicacio- nes para la Administración Pública
}

Vincent Wright*

Redefinir los Estados de la Europa occidental tiene implicaciones directas para sus respectivos sectores públicos. La amplia presión convergente ha llevado a programas de reforma mayoritariamente similares. Sin embargo, las diferencias permanecen en Europa occidental en lo que a la naturaleza, estilo, tiempo y evolución de las reformas respecta. Estas diferencias pueden ser explicadas analizando la naturaleza de dichas presiones, el tamaño y espectro del sector público tradicional, las ambiciones de los gobiemos, así como su compromiso ideológico y la durabilidad política, las estructuras de la política doméstica y la oportunidad administrativa. Los programas de reforma que se persiguen en varios países están caracterizados por distintas contradicciones y numerosas paradojas.

El proceso de redefinición del Estado, a lo largo y ancho de Europa occidental, ha tenido inevitables consecuencias para las empresas públicas, las relaciones gubernamentales, y para las Administraciones públicas centrales, siendo estas últimas donde se centrará principalmente este artículo, que empieza describiendo las presiones que están definiendo esas Administraciones. Seguidamente, se presentará la general y ampliamente respuesta programática en Europa occidental. Tras ello serán exploradas y explicadas las diferencias entre los distintos programas. Finalmente, se examinarán las paradojas de todos ellos. E] argumento general del arículo es que las presiones convergentes que están redefiniendo los Estados de Europa occidental, combinados con otras, tienen inevitables efectos directos o indirectos, sobre sus Administraciones públicas, empujando a los gobiernos a reformas amplia y crecientemente similares. Sin embargo, permanecen diferencias significativas en la naturaleza, intensidad, tiempo y ritmo de las reformas. Estas diferencias pueden explicarse en términos de las oportunidades ofrecidas por el entomo político-institucional y cultural en los que se persiguen. Más aún, muchas de las reformas, que tienen errores a distintos niveles, pueden tener consecuencias no previstas, indeseadas y paradójicas.

\section{Presiones para la reforma del sector público}

Desde el principio de los años 80 la reforma administrativa ha ocupado un lugar importante en la agenda de la mayoría de los Estados de la Europa occidental. Así, los informes de la OCDE sobre "Desarrollo de la Gestión Pública" de los años 90 revelan una intensidad casi frenética acerca de los programas de reforma. El Reino Unido está, característicamente, en la vanguardia del movimiento, con reformas en todos sus frentes, y particularmente en la extensión de la iniciativa Next Steps. Las reformas han sido planteadas por gobiemos de derechas (Reino Unido, Grecia, Nonega), por coaliciones (Alemania, Italia, Países Bajos) o por gobiemos socialistas o social-demócratas (España, Suecia, Francia). Podría, por lo tanto, parecer que la Europa occidental ha entrado verdaderamente en la época de reforma administrativan después de años de cambio esporádico, pragmático y limitado, a menudo engendrado internamente. Tal vez, esto no resulte sorprendente, dado que los Estados de la Europa occidental están siendo forzados a cambiar por presiones convergentes e interconectadas. Algunas de ellas merecen ser enfatizadas, porque cada una está preñada de implicaciones administrativas. Estas presiones pueden resumirse como sigue:

- Internacionalización de los mercados industrial y financiero, lo que está creando grandes problemas de coordinación administrativa internacional, transnacional o transfronteriza, y provocan, en ciertos sectores, un desajuste entre las estructuras administrativas nacionales, los procedimientos y el personal, y la gestión administrativa de los nuevos requerimientos regulatorios internacionalizados. Más aún, la internacionalización ha supuesto, algu- 
nas veces, crecientes conexiones entre empresas (empresas colectivas, intercambio de acciones, acuerdos de investigación o comercialización, ganancias minoritarias) no sólo en países diferentes sino también entre las empresas públicas y privadas. Este aumento de la hibridación extranjero/nacional, público/privado - a menudo motivado por gobiernos europeos occidentalesestá desdibujando no sólo la identidad, sino también las líneas de responsabilidad para los administradores públicos ${ }^{1}$.

- El impacto de ser miembro de la Unión Europea, lo que ha supuesto un creciente aumento del impacto normativo de Bruselas en sectores (tales como la ciudadanía, el medio ambiente, la protección al consumidor, e incluso la cohesión social), exclusivamente domésticos anteriormente, planteando así temas de información y coordinación administrativa, así como cuestiones complejas de personal y "cultura administrativa. La Unión Europea tiene implicaciones indirectas para los sectores públicos nacionales, especialmente a través de las consecuencias de la convergencia monetaria (con sus requerimientos de una mayor disciplina presupuestaria), su política de la competencia (lo cual conlleva consecuencias a largo plazo para sectores públicos nacionales protegidos), sus extensas áreas políticas reguladas, y su creciente papel funcional ${ }^{2}$. Ser miembro de la Unión tiene tanto requerimientos administrativos reactivos (ajustes al impacto) como proactivos (creando nuevos cuerpos administrativos para explotar el potencial de la Unión). Estos últimos pueden ser más notablemente observados a nivel regional ${ }^{3}$. El impacto de la Unión puede verse más dramáticamente en la implementación del artículo 48 del Tratado de Roma y la celebrada decisión del Tribunal (Comisión v. Bélgica, 17 de diciembre de 1980) la cual abrió muchos, efectivamente casi todos, los puestos nacionales del sector público a ciudadanos de otros Estados miembros. Un Estado miembro puede reservar para sus propios ciudadanos sólo aquellos puestos que requieran aparticipación, directa o indirecta, en el ejercicio de poder público. y funciones que tienen como objetivo sla salvaguardia del interés general del Estado y de otros cuerpos políticosn. Por supuesto, esto no significa que las Administraciones nacionales hayan sido europeizadas en su composición. Pero ciertos puestos (a menudo a disgusto) se han ofrecido en muchos países donde un principio sacrosanto establecía que sólo ciudadanos nacionales podían servir al Estado.

- Presiones económicas y financieras, causadas por problemas de deuda y déficit públicos, de rentas públicas del Estado y resistencia fiscal, y exacerbadas por las exigencias del criterio de Maastricht, han tenido un impacto directo en presupuestos administrativos y en el personal. Esta es probablemente la única gran presión (l'aguillon de base) para la reforma, y esto ha sido confesado abiertamente por varios gobiernos ${ }^{4}$. El eslogan la fiesta ha terminado. del Reino Unido de los tardios años 80 , ha encontrado una traducción directa - la festa è finita- en Italia en 1994. Y no es sólo el gobierno conservador británico el que insistió en que el sector público diera vvalor al dinero incrementando su eficiencia.

- El cambio paradigmático general, con su fuerte prejuicio ideológico contra el Estado, el gran gobiemo, las abotargadas burocracias y las soluciones universalistas. En lo que a las Administraciones se refiere, el paradigma no ha sido alimentado solamente por economías orientadas hacia el estilo Chicago de mercado, sino también por teorías de elección pública (con sus simples nociones de comportamiento burocrático), por la teoría de agente-principal, por nuevas teorias de derechos de propiedad, y por análisis económicos del fracaso del sector público '. Una de las claves para entender este cambio paradigmático es llegar a la idea de que el ciudadano, un concepto problemático para los neo-liberales, es un consumidor individual, $\mathrm{o}$, un cliente de servicios públicos, y tiene derecho a ciertos niveles de servicio, comprobados analizando sus rendimientos. Este avance desde la "época del cliente cautivo a la del consumismo" está lleno de consecuencias para el paradigma del tradicional servicio público ${ }^{6}$.

- El cambiante programa político en muchos países de la Europa occidental, con la creciente prominencia política de problemas tales como el medio ambiente, el tráfico de drogas y la ley y el orden; muchos de los cuales requieren nuevos cuerpos administrativos nacionales, transfronterizos o internacionales y cooperación, y muchos de los cuales necesitan expansión burocrática? .

- El rápidamente cambiante entomo político, especialmente en Alemania, la cual se enfrenta a la tremenda tarea de absorber los cinco Länder orientales, en Italia donde está cambiando a las Repúblicas en circunstancias impredecibles, en España la cual está siendo testigo de las crecientes actividades dinámicas y autónomas de ciertas regiones, en Gran Bretaña, que ha dado recientemente la gran mayoría a un modernizador Partido Laborista, tras un largo período de hegemonía conservadora, y en Bélgica, que ha presenciado la casi total desintegración de las tradicionales estructuras adminis- 
trativas bajo el impacto del duradero conflicto entre los Flamencos y los Valones.

- El cambio tecnológico, - la explosión de las llamadas tecnologias informativas convergentes (CIT) - provocando una creciente relación íntima entre telecomunicaciones, elaboración de datos por ordenador y productos automatizados de oficina. Todas las implicaciones para el sector público tienen todavía que ser totalmente aceptadas, más aún absorbidas, pero el impacto ya se siente en las tradicionales jerarquías burocráticas del Estado, en las estructuras organizadoras, en las prácticas y habilidades, en la gestión de personal y la prestación de servicios $^{8}$. La nueva tecnología está también transformando la naturaleza de algunas industrias del sector público, haciendo obsoleta la noción de monopolio natural, y transformando empresas monoproductoras de base nacional en grupos multiproduccionales internacionalizados, que son más dificiles de administrar.

- La presión democrática, con sus muchos y claramente conflictivos embarrancamientos y problemas: más y mejores servicios, pero más baratos; mayor efectividad, pero también mayor transparencia y acceso; más rápidas decisiones, pero mayor participación y consulta ciudadana; autodirección y democracia industrial; representación (para mujeres, grupos étnicos, minorías raciales, clases no privilegiadas, gente discapacitada), pero, sin embargo, ingreso y promoción en la Administración por méritos. Cada una de estas exigencias está cargada de problemas ${ }^{9}$. No está nada claro, por ejemplo, lo que se entiende por "burocracia administrativan, cuyo significado ha cambiado con el tiempo y que ahora incluye exigencias conflictivas. Sin embargo, estas exigencias impactan sobre la moda administrativa (y en una impredecible predicibilidad y una ambigua inambigüedad y cuestionable incuestionabilidad), aumentando el sentido de desorientación que aflige a las Administraciones públicas en muchos países.

Estas presiones se han sentido a nivel de todos los Estados europeos, y han tenido repercusiones indirectas pero automáticas para sus sectores públicos. Otras dos grandes presiones comunes han afectado más específicamente a esos sectores:

- El descontento generalizado ante la actuación del sector público, el cual ha tomado distintas y conflictivas formas a lo largo de Europa occidental, y a menudo dentro de cada país europeo. Según se afirma el sector público es o demasiado poderoso y demasiado intrusivo o demasiado débil y demasiado inefectivo, demasiado politizado y demasiado obligado por gratitud a los políticos o demasiado independiente y no lo suficientemente sensible a las exigencias de sus dueños políticos.
En casi todos los países también se le acusa de libertinaje, ineficiencia, oscuridad, y en algunos es justificablemente juzgado como comupto. No es sorprendente que algunas teorías de elección pública, con sus críticas acerca de las tendencias intrinsecas de los burócratas orientados hacia sí mismos, se conviertan en los fundamentos filosóficos de moda y la racionalización para los distintos programas de reforma. Tampoco es sorprendente que las criticas de intervencionismo estatal (basadas en su inherente ineficiencia comparado con el mercado) se entremezclen con las de la burocracia (enraizadas en oficiales orientados hacia sí mismos, buscando solamente la expansión de sus imperios y la maximización de sus presupuestos). No es menos sorprendente que los políticos, buscando cabezas de turco para sus propios fracasos y en su búsqueda de remedios fáciles para problemas inherentes a la dirección de las crecientes demandas para el Estado con medios cada vez más limitados, acepten, quizá demasiado rápidamente, parte o todo la crítica neo-liberal del sector público. Ciertamente, si el sector público no pudiera ser abolido, o radicalmente rebajado, (y muchos piensan que podría) debería ser reformado. Este deseo de reforma ha sido compartido por los gobiernos de todas las tendencias políticas, y ha encontrado un eco favorable entre algunas de las élites modernizadoras de la Administración pública. Estas son algunas veces eeconócratas", criadas con una dieta de economías clásicas, y que no están corrompidas por los instintos sujetos a reglas de los abogados, ni por el perezoso escepticismo inducido por el estudio de la historia o de la ciencia política. En algunos casos hay funcionarios que eburomoldean" (bureaushaping) (utilizando la descripción de Patrick DuNLEAVY), a menudo más interesados en la formación política y el control que en la tarea, menos exaltada, de implementarla. En muchos casos, sin embargo, son funcionarios públicos dedicados al servicio público y empeñados en mejorarlo ${ }^{10}$. Cualquiera que sea la razón, muchos no han necesitado ninguna motivación para reaccionar a la siguiente presión:

- La llamada revolución gerencial, que ha puesto en tela de juicio los procedimientos, técnicas y estilos tradicionales, y afirma que la eficiencia reside en unidades direccionales más pequeñas, más descentralizadas, más flexibles, más especializadas, y más autónomas, dirigidas por jerarquías aplanadas con un mayor nivel de participación de los escalones más bajos. Para OsBORNE y GAEBLER, quienes en su crítica postmodernista, vulgarizaron en su gran éxito Reinventando el gobierno ${ }^{11}$ las nuevas ópticas, las grandes organizaciones públicas jerárquicamente estructuradas e integradas, sujetas por 
múltiples niveles de leyes o regulaciones, que emergieron durante el período de crecimiento del gobierno, de producción masiva y paternalismo y de uniformidad, ya no son apropiados en una era de flexibilidad, de elección y responsabilidad personal. ¡Curiosamente, este mismo argumento se hacía algunos años antes por ciertos Socialdemócratas suecos! ${ }^{12}$. La Administración pública tradicional era, también según las críticas, gerencialmente errónea por su obsesión en acatar las reglas y las regulaciones y por respetar el esperado proceso. Efectivamente, según se alega por muchos funcionarios del sector público, la buena administración reside en la aplicación uniforme e inflexible de la ley y de los procedimientos establecidos. A los objetivos, rendimientos y realización se les otorga una atención insuficiente. Dada la creciente capacidad del sector público de definir tales objetivos y medir los rendimientos y la realización, esto no era sólo lamentable sino inexcusable. Más aún, aparentemente se estaban realizando exitosos experimentos en la reducción del sector público y en reforma en un país europeo, que se están convirtiendo en modelo para varios de sus vecinos. El programa de privatización británico -y particularmente sus lucrativos rendimientos- ha inspirado a muchos de sus vecinos europeos hambrientos de renta (la "industria de privatización", se ha convertido en uno de los pocos exportadores exitosos de Gran Bretaña), y su radical búsqueda de una "nueva gerencia pública" (ver más abajo), basada en técnicas y estilo del sector privado, ha sido también cuidadosamente estudiada en muchos Estados europeos (notablemente en los Paises Bajos, Dinamarca y Noruega). La emulación política es particularmente clara en los programas de reforma de España e Italia, los cuales han sido definidos por ministros conocedores de experiencias extranjeras: el Ministro español para la Reforma Administrativa, un académico, estudió cuidadosamente los programas suecos, holandeses, franceses y británicos, mientras que el Ministro italiano, otro académico, es un sobresaliente experto en administración pública. La Nueva Gestión Pública (New Public Management (NPM)), está basada con respecto a la sustancia y no al proceso, en la construcción y el asesoramiento específico, más que en la objetividad y las metas, en tratar al público como clientes, en motivar la competitividad entre proveedores de servicio, en la descentralización de la toma de decisiones, en mejorar las técnicas de gestión e introducir indicadores eficientes y técnicas de plan corporativista y en explotar las prácticas gerenciales de recursos humanos privados y los servicios de información ${ }^{13}$. Se ha convertido en una nueva moda o manía, una penetrante Zeitgeist difundi- da por cuerpos internacionales (tales como la OCDE), gobiernos nacionales ${ }^{14}$, escuelas de negocios, ejércitos de consultores e institutos de investigación, pero su éxito reside en la propicia naturaleza del terreno político que ha penetrado ${ }^{\text {s. }}$.

El sector público como agente principal del Estado está, por lo tanto, atrapado en el cruce de caminos de estas múltiples presiones altamente convergentes y conflictivas. Las presiones en el Estado se traducen inmediatamente en presiones en el sector público. $Y$ hay evidencia de que presiones convergentes están llevando a ambiciones programáticas convergentes y rendimientos.

\section{Respuestas programáticas}

Aunque la Europa occidental parece estar en una frenética actividad de reforma administrativa, es útil distinguir entre los distintos tipos de programas de reforma:

1) Las reformas que son parte de un proceso que sigue, de modernización generalmente internamente inducida. Eștos incluirían los progresivos y graduales ajustes a la calidad de miembro de la Unión Europea y a la creciente internacionalización ${ }^{16}$ y a la progresiva, aunque problemática, introducción de nuevas tecnologías ${ }^{17}$.

2) Las reformas que son introducidas por los gobiernos como respuesta a presiones políticas específicas. Éstas incluirían la dramática reestructuración de la Administración central en Bélgica (donde los ministerios se han dividido en base a la lingüistica), la clarificación y reorganización de la Administración de la Alemania del Este, tras la reunificación, y la creación de un horizonte centralmente localizado y cuerpos verticales de relaciones intergubemamentales en la regionalización de países como España e Italia.

3) Las reformas que son introducidas por los gobiemos de forma gradual, pragmática e instrumentalista -que es el caso de reformas que afectan a las estructuras organizacionales-, en la mayoría de los países.

4) Las reformas que se necesitan para la gestión de los anteriores programas de reforma. Así, la privatización de los monopolios públicos en el Reino Unido y Alemania ha llevado a la creación de agencias reguladoras, mientras que la descentralización, una de las principales respuestas político-administrativas a las presiones sobre el Estado, ha exigido, a menudo, considerables reformas administrativas a nivel nacional ${ }^{18}$. Las innovaciones tecnológicas son tanto una respuesta, como una fuente de reforma administrativa. 
5) Las reformas que corresponden a un programa comprensivo, y que son parte de un mayor programa de cambio políico. En cierto sentido, el programa de reforma británico, discutiblemente el más radical de Europa occidental, no ha sido nunca estructurado por una más que dolorida estrategia. Más bien se tropezó con ello, se desarrolló en la pezuna y se alimentó de su propio aparente éxito. Las razones se inventaron después de la implementación. A un nivel más profundo, sin embargo, se podría asumir que el programa ha cobrado una coherencia y una racionalización que está encajado en ese grupo más amplio de instintos anti-Estado y prejuicios, que han informado al Gobierno Conservador británico desde 1979. Como en Suecia, parece haber avanzado, después de la reforma del sector público desde 1982, de ser una actividad ad-boo (creada exclusivamente para esa actividad), a ser una "política pública" (citando los términos de MARCH y OISEN) ${ }^{19}$. Los programas que abarcan todo, a menudo fundamentados en presiones antiestatales, si bien en una forma atenuada, pueden verse en las reformas del primer gabinete de Lubber (19821986) en los Países Bajos, y en la de 1983 del gobierno Conservador-liberal en Dinamarca. No puede decirse lo mismo del amplio espectro de programas de los socialistas españoles (el Plan de 1992 de Modernización de la Administración del Estado contenía no menos de 204 propuestas); del gobierno de Rocard en 1989 en Francia (que quería avanzar de una administration de procédure. a una administration de responsabilitén), del programa de noviembre de 1990 del recién elegido gobierno Socialdemócrata en Noruega; de los Socialdemócratas suecos que volvieron al poder en 1982 tras seis años de poder de coalición de derechas, y quienes en 1985 presentaron un amplio paquete de reforma, o de "la cura Cassese, el programa de Reforma Radical (el Indirizzi per la modernizzazione delle admministrazioni pubbliche, proponía 36 ambiciones de reforma bajo diez títulos principales), del gobierno de Ciampi de 1993 en Italia, nombrado como el ministro responsable del "pachetto. En todos estos casos, el deseo no era el de desmantelar o debilitar el aparato estatal, sino simplificar y modemizarlo, o como parte de un programa de modernización estatal de más largo alcance, o solamente por razones instrumentales.

¿Qué programas de reforma administrativa se siguen en Europa occidental? Según el país estudiado, pueden implicar o un ajuste marginal o un cambio radical, o implicar varios niveles interconectados, y se resumirían como sigue ${ }^{20}$ :

I. Reducción del sector público nacional en tamaño, recursos, espectro e influencia. Esto puede verse en intentos, no del todo exitosos, para reducir o estabilizar el número de funcionarios. Esta política ha sido notablemente seguida en Grecia (el gobierno de Nueva Democracia en 1992 se dedicó a una política de euna sustitución por cada dos funcionarios retirados.), en Portugal (que ha sido testigo de una explosión del número de empleados públicos durante los años 70 y 80), en Finlandia (el objetivo del presupuesto de 1992 apunta a reducir el tamaño de la Administración en un 5\% para 1995), en los Países Bajos (los cuales, en 1992, apuntaron a una reducción de 9.000 para 1994), en Suecia (con su ambicioso Plan de octubre de 1990, diseñado para reducir la Administración pública nacional en un $10 \%$ en un período de tres años), en Francia (que en 1987 decidió reducir el número de admitidos en la ENA, su escuela de élite de enseñanza administrativa, a la mitad), y ahora en Italia. Pueden verse unas disminuciones similares en los números de personal en Dinamarca, y en menor grado, en Austria y Alemania. El campeón de los recortes es, por supuesto, el Reino Unido, que ha visto una reducción en el número de funcionarios de más del 10\% entre 1987 y 1996, aunque la realidad es menos dramática de lo que las estadísticas y el gobierno insinúan ${ }^{21}$.

Las reducciones en los recursos han afectado a todos los sectores públicos nacionales, obligando a muchos a hacer politicas de regresión gerencial ${ }^{22}$. De todas formas, los datos agregados disimulan considerables variaciones en las áreas políticas, $y$, en cualquier caso sugieren que no siempre las ambiciones radicales se han traducido en rendimientos efectivos.

El espectro del sector público ha sido más marcadamente reducido por la política de privatización, especialmente en el dominio industrial. El Reino Unido y Francia han sido privatizadores industriales más radicales, aunque otros países, tras un comienzo lento y lleno de dificultades, están ahora extendiendo los límites y acelerando el paso de sus impulsos de privatización ${ }^{23}$. Sin embargo, la privatización, en el sentido de la transferencia al "por mayor al sector privado, ha sido mucho menos aparente en los servicios públicos y áreas del Estado del bienestar, aunque algunas políticas limitadas se han emprendido en el Reino Unido ${ }^{24}$ y en los Países Bajos.

El intento de reducir el espectro del ámbito público se puede también ver en las políticas de desregulación o, más específicamente, en las de desburocratización -el anulamiento de normas y regulaciones, que han crecido en número y complejidad y que son u obsoletas o impiden el objetivo de una política gubernamental-. Entre las campañas de desburocratización más notables se encuentran las de Alemania (el Gobierno Federal instituyó en 1983 un Comité encargado de la tarea de identificación de regulaciones inútiles), y Gran Bretaña (la promesa del Presidente del Comité de Comercio, Michael Heseltine, de 1993, de una hoguera de regulaciones", fue un programa muy anunciado aunque inefectivo). En Portugal, en octubre de 1990, el gobierno de Cavalho Silva instituyó incluso un Día Nacional 
de Desburocratización, que se celebraría cada último martes de octubre, con el objetivo de concienciar sobre el problema y de producir iniciativas para resolverlo. Como en muchos otros países, se ha creado un grupo de proyecto para seguir el proceso $\multimap$ la falta de él-. En Gran Bretaña se establecieron en 1993 siete de estos grupos.

- El tamaño, recursos y espectro del sector público nacional también ha sido reducido, a menudo drásticamente, por políticos descentralizadores, o a las regiones (Bélgica, España, Italia), o a los departamentos y los municipios (Noruega, Suecia, Dinamarca). Gran Bretaña fue la excepción notable, bajo el gobierno conservador de 19791997, el cual impuso una política de descentralización sin precedentes -una política que está ahora siendo radicalmente revisada por el gobierno de Blair-.

- Reducir la influencia directa del Estado ha adoptado varias formas más notablemente en las políticas de privatización encubierta (otorgando mayor autonomía a las empresas públicas estatales y privatizando su gestión $\mathrm{u}$ objeciones - una política que puede verse en casi todos los países que conservan un extenso sector público-), y en la delegación política tanto a cuerpos administrativos independientes o regulatorios, como a cuerpos del tercer sector . Los años 80 y principios de los 90 han visto la proliferación de autoridades administrativas regulatorias independientes, que se encuentran fuera de la Administración estatal, definida tradicionalmente, o del gobierno local, y a las que se les confian tareas públicas. Así como la políica y difusión de la competitividad de los mercados financieros y de seguros están siendo crecientemente regulados por dichos cuerpos y no directamente por las Administraciones estatales ${ }^{25}$.

También puede verse la política de desregulación en la ampliación del espectro de tareas públicas llevadas por cuerpos del tercer sector - generalmente sin beneficios- que son agentes privados de la política pública. ${ }^{26}$ dando gobierno por poderes" 27 (delegando) en áreas tales como la educación, la sanidad y las pensiones ${ }^{28}$. Dichos cuerpos siempre han jugado un prominente papel de hacedores de política en países como Alemania y los Países Bajos. Ahora se están extendiendo al sur de Europa.

II. Mejorar la capacidad de seguimiento de la administración, reformando los procedimientos de planificación y evaluación presupuestaria del sector público -en un intento de adquirir mayor valor por el dinero-, basado en las tres :Es: economía, eficacia, efectividad. Esto está estrechamente unido a las reformas de gestión, tecnología y comercialización. En el fondo, implica estrechar los controles y la responsabilidad, y mejorar la intervención y evaluación de objetivos mejor defini- dos, a menudo en forma de contratos ${ }^{29}$. Como cualquier académico británico afirmaría, la evaluación se ha convertido en una locura política desde la mitad de los años 80 . Pero ningún otro país europeo ha escapado de la manía. Incluso Suiza, el menos reformista de los países de la Europa occidental, se ha unido al vagón de seguimiento (siguiendo las medidas adoptadas en febrero de 1990). Muchos de los cuerpos se han establecido o mejorado para llevar a cabo la intervención y la evaluación: la Comisión de Intervención (1983) en Gran Bretaña para el gobierno local, y después al Servicio de Salud Nacional, seguidos por la Oficina Nacional de Intervención (1984) para el gobierno central; para Suecia, la Revisión de Riesgo Verket; el Conseil Scientifique de l'Évaluation, el Comité interministériel de l'évaluation, y los Fonds nationaux de développement de l'évaluation en Francia; la recién creada (1993) oficina en la Conte dei Conti en Italia ${ }^{30}$. En algunos casos, incluso esos cuerpos instituyen los indicadores de actuación que han de ser probados (como es el caso de la Comisión de Intervención en Gran Bretaña).

III. Mejorar la gestión del sector público, el cual ha permanecido bien como un proceso incremental y ad hoc, o bien desarrollándose como parte de una revolución. gerencial más amplia y teóricamente más coherente. Los Conservadores británicos han perseguido la estrategia de la Nueva Gestión Pública (NGP) con el mayor apremio, empezando con los escrutinios de Rayner de departamentos individuales, y en el Informe Griffith (1983), por la necesidad de introducir gerentes en el Servicio Nacional de Salud, y después en la Iniciativa Financiera de Gestión, entonces ampliada para abarcar mayores metas. También se le han añadido fundamentos intelectuales e ideológicos ${ }^{31}$. Sin embargo, los Social-demócratas suecos, y los Socialistas españoles y franceses, incorruptos por las mismas motivaciones ideológicas, no han sido menos entusiastas. La NGP se ha convertido en una ideología en sí misma, y en una dominante en muchos círculos políticos y en escuelas de gestión pública, y está siendo lentamente difundida por Europa occidental: en 1991 se estaban dando los primeros tímidos pasos en Italia. Muchos de los rasgos dominantes de la NGP vienen de un programa de reforma más amplio, y pueden ser resumidos como sigue ${ }^{32}$ :

- Fragmentación: esto puede observarse a distintos niveles. En primer lugar, puede verse a nivel de realización de política, con la separación de la decisión política de la ejecución. Un pequeño grupo de hacedores de politica de la Administración central deberían ser servidos por un anfitrión de agencias traspasadas y autónomas (en términos operacionales y presupuestarios). Este sistema de autogobierno interno o agenciación que tiene unas largas e históricas raíces en Suecia, ha sido adoptado en los Países Bajos (con el informe, de 1983, de la Mejora de la Actuación en las Organizaciones Gubernamentales), en Dinamarca, y en Francia. También se han 
introducido medidas para mejorar la autonomía para los gestores en Austria, en Italia (desde 1992) y en España (la Ley Presupuestaria de 1992 establecía dos agencias piloto, una en el servicio de recaudación de impuestos, y la otra en los servicios postales). En Noruega, el nuevo gobierno Social-demócrata decidió, en noviembre de 1990 , otorgar una mayor autonomía a operaciones de todos los días a las agencias existentes. Esta política de dividir la prestación de servicios de la puesta en marcha de políticas públicas a través de las agencias autónomas ha recibido su mayor expresión en Gran Bretaña, con la introducción de la Iniciativa de los Next Steps en 1988. Emprendida en 1988, con la Inspección de Vehículos, involucraba a 49 agencias incluyendo a un tercio del funcionariado para finales de 1991. Para el fin de 1993 había más de 90 agencias y se habían identificado a 44 candidatos. Para el comienzo de 1996 cuatro quintos de los funcionarios habían sido transferidos a agencias ${ }^{33}$. La división comprador/proveedor (otra, pero relacionada forma de fragmentación) es claramente evidente en el gobierno local y en el Servicio de Salud Nacional, el cual ha sido testigo de la creación y del rápido crecimiento del número de empresas hospitalarias autogobernadas y de expertos en fondos familiares, que han sido empujados fuera del control de las autoridades locales. En este desagregado mundo administrativo, las jerarquías integradas han dado paso a agentes independientes cuyas relaciones están reguladas por contratos. El servicio público ha tomado, así, la apariencia de constituir nexos de contratos o tratados ${ }^{34}$.

- Regulación: la meta del sector público no es la provisión sino la regulación: de ahí, la extendida y creciente influencia de las agencias reguladoras. Para garantizar su independencia están separados de los clientes y de los proveedores.

- Competitividad: esto está inducido por una completa privatización, desregulación, o con el sector público por la comercialización, basado en mercados internos (como en los servicios de salud del Reino Unido, los Países Bajos y Alemania), contratando, y ofertando (a menudo obligatoriamente), bonos. A mediados de 1996, la prueba de mercado de Gran Bretana había puesto los empleos de 30.000 funcionarios en competición ${ }^{35}$, y grandes partes del sector público (incluyendo, no sólo la provisión de alimentos, el servicio de ordenadores, la combinación para especular en valores públicos de coches, y la gestión de propiedades, sino también áreas más delicadas como el mantenimiento de helicópteros y la reparación de barcos para las fuerzas armadas, la dirección del modelo de Tesoreńa económica, los cursos anfibios de entrenamiento para los Marinos Reales, la producción de pasaportes, y la seguridad para las Armerías Reales) habían estado sujetas a pruebas de mercado y oferta competitiva. La idea consiste en construir sustitutos o mercados sociales que dupliquen, en la medida de lo posible, las presiones sobre el sector público para conseguir la eficiencia y calidad que existen en el sector privado.

- Gestión directa gozando de una mayor visibilidad, responsabilidad y discreción.

- Precisión: NGP es gestión por objetivos o precisos planes corporativos, definidos por contrato, y basado en metas, medidas o indicadores de actuación explícitos. Ha sido ampliamente introducido desde la Inglaterra thatcheriana a la España de Felipe González ${ }^{36}$.

- Orientación de los rendimientos: el énfasis se desplaza de los procesos a los resultados, con recompensas, incluyendo pagas, asociadas a la actuación. La evaluación se convierte en un elemento clave de la NGP.

- Privatización: de la gerencia del personal, estilos y procedimientos (gestión de calidad total, círculos de calidad, flexibilidad en contratar y despedir, incentivos y sanciones). La ética tradicional del servicio público debe ser reemplazada por una basada en la calidad de empresario o contratista, en la iniciativa personal y en correr riesgos ${ }^{37}$.

- Parsimonia: en la distribución de recursos, con una mayor sensibilidad para el conte de costes y la disciplina financiera.

- Clientelización: la tarea del sector público no es gestionar al conjunto de ciudadanos, sino servir a los clientes -algunas veces, según los contratos de calidadcomo en la Citizens Charter de julio de 1991 en el Reino Unido, o la Charte des services publics de marzo de 1992 en Francia.

IV. Desmantelar la estructura estatutaria tradicional para funcionarios que estaba basada en:

- Permanencia: los funcionarios con contratos temporales aumentaron drásticamente en países como Francia (se triplicaron entre 1981 y 1991, hasta llegar a 150.000 en ese año) e Italia.

- Estabilidad (tenure): ahora es más fácil despedir a funcionarios en varios países como Francia (desde el Acta del 30 de julio de 1987) e Italia donde el posto sicuro ya no es sicuro, como resultado de una decisión de diciembre de 1993. Un plan británico de 1994, realizado por la Unidad de Eficiencia (Efficiency Unit), depen- 
diente del 10 Downing Street, contempla el desempleo obligatorio para trabajadores de bajo nivel y funcionarios "que sobrepasen las necesidades.

- Trabajo a jornada completa: los trabajadores con dedicación parcial están empezando a ser reclutados en varios países de la Europa occidental.

- Igual salario para personas del mismo rango. el salario en función de la actuación es un rasgo común de las burocracias europeas, incluyendo a Gran Bretaña, Austria, Suecia, Francia, España, Portugal, Grecia, Dinamarca y los Países Bajos. La decisión noruega de 1992 de pagar a 450 gestores públicos veteranos según contratos de actuación individual, es tan sólo uno de varios de esos planes. Esta creciente individualización del sector público se corresponde con su balcanización oficialmente motivada $-\mathrm{y}$ no sólo en sus estructuras organizacionales - La misma noción de un funcionariado unido - un grand service public - está amenazada. Y si la negociación nacional de salarios - una de las expresiones de su unidad- permanece intacta en la mayoría de países, hay claros signos de erosión en otros ${ }^{38}$.

- Una definida distinción entre público-privado: no sólo se están organizando programas de formación en gestión pública por organismos privados (como en Francia, por ejemplo) o están siendo crecientemente imbuidos con una lógica del sector privado (como en el Reino Unido), sino que se están haciendo intentos para atraer cierto número de gestores del sector privado hacia el servicio público: se han realizado intentos de abrir la ENA en Francia al sector privado, y en el Reino Unido la Unidad de Eficiencia (Efficiency Unit), en noviembre de 1993, sugirió que se ofertaran e hicieran competitivos los puestos más veteranos de la administración pública, un plan bienvenido por el Primer Ministro Major ${ }^{39}$.

V. Democratizar el sector público de varias formas: permitir un mayor uso de encuestas públicas; asegurar mayores, si no iguales, oportunidades en el reclutamiento o promoción en la Administración, y especialmente entre sus élites (la ENA en Francia, los cuerpos superiores en España) para mujeres, población de clase trabajadora, minorías étnicas o lingüísticas, y los físicamente discapacitados; dar a los más bajos escalones de la Administración voz en la toma de decisiones a través de la introducción de círculos de calidad. Incluso ha habido experimentos de prueba en la democracia de los lugares de trabajo y la codeterminación en algunos países.

VI. Hacer al sector público más amigo del usuario, siendo más abierto, teniendo mayor visibilidad, correspondencia y res- ponsabilidad personal. Las reformas, bajo este título, incluyen el nombramiento de funcionarios (personalización), la simplificación de los procedimientos administrativos, reduciendo su número, reduciendo el número de firmas necesarias para cualquier transacción (como en Grecia), o por las campañas de •ventanilla única en Francia e Italia, cuya meta es la eliminación de un cierto número de unidades dentro de un departamento implicado en los temas con el usuario. También incluirían facilitar el acceso a clientes, dando a los ciudadanos mayor acceso a sus propias fichas y a la información gubernamental (se han facilitado Actas de Información en casi todos los países) y fortalecer las instituciones y los procedimientos de quejas ${ }^{40}$. En ciertos países se ha hecho un verdadero esfuerzo para mejorar la imagen de la Administración a través de campañas de relaciones públicas bien orquestadas y en algunos cursos de gestión pública se subraya el desarrollo de la "Clientelización" del sector. En Irlanda se han organizado talleres para sensibilizar a los directores públicos de las necesidades de sus •clientes".

VII. Reorganizar las estructuras del sector público. La respuesta a los cambios mencionados anteriormente ha requerido cierta capacidad de innovación y renovación institucional: reducción, remezcla y creación ministerial (nuevos ministerios para los asuntos medioambientales, para asuntos de mujeres y para la reforma administrativa); nuevas agencias reguladoras y coordinadoras, controladas por el Estado a nivel internacional, de la Unión Europea y nacional; nuevas agencias semiautónomas en los departamentos; nuevos cuerpos para motivar el cambio tecnológico (como por ejemplo el Comité interministériel de l'Informatique et de la Bureaucratique dans l'Administration francés); nuevos o reforzados cuerpos de intervención o de evaluación (ver arriba); una proliferación de instrumentos para apadrinar y seguir la reforma administrativa, (cellules de modernisation en Bélgica, la Inspección General de Servicios de la Administración Pública (IGSAP) en España, el Observatorio de Productividad Central en Alemania, el Gobierno Comisionado para las Reformas Administrativas en los Países Bajos; la Unidad de Eficiencia en la Presidencia del gobierno, la Unidad de Competición Pública y de Compra en la Tesorería, y más recientemente, en el Reino Unido, la Citizen's Charter unit, la Office of Public Service and Sciences). El entorno organizacional administrativo había desafiado todos los intentos de simplificación.

Y la agencificación (ver abajo) ha añadido simplemente unas pocas dimensiones complejas.

VIII. Transformar la cultura del sector público, según el viejo adagio sobre hacer que el negocio del gobiemo se parezca lo menos posible a un negocio. El sector público debería ser empresario en espíritu, dirigido por una camada de más ‘robustos funcionarios, y atendido por oficiales sensibles al sector público y a sus aclientes, los cuales están más empeñados en la economía que en el Derecho, más preocupados por el dinero 
líquido y el balance de los beneficios y los gastos, y que prefieren el mercado a reglas formales, y la competitividad al orden burocrático. Según las palabras del Programa de Reforma de 1985 de los socialistas españoles, pero que podían haber sido dichas por cualquier thatcheriano, la Administración debería -sentirse orgullosa de obtener resultados y deshacerse de sla vieja cultura legalista. ${ }^{41}$. O, citando la ambición del gobierno socialdemócrata sueco: hay una necesidad de avanzar desde suna cultura de autoridad. a un servicio cultural. ${ }^{42}$.

-Reducir tamaño, ,utilizar al máximo los recursos, cut-back management, efectividad económica, eficiencia, privatización, outsourcing, ‘comercialización', nueva gerencia, •contratación., "competitividad, ‘clientelización, ‘reestructuración, «democratización, aautonomización', •agencificación, éstas son sólo algunas de las muchas fuerzas que actualmente afectan al sector público. Pero, la extensión, intensidad, mezcla, medida del tiempo y paso difieren ampliamente a lo largo de Europa occidental. Existe el peligro de ver el mundo administrativo a través de la óptica anglo-americana: el movimiento de la reforma administrativa, cuando existe, tiene una tradición contrastada en base a una inspección más detallada.

\section{Diferencias políticas: hacia una explicación}

Hay una ausencia singular de datos comparativos fiables sobre los programas de reforma administrativa que se están ejecutando en la Europa occidental ${ }^{43}$. Sin embargo, cierta cantidad importante de evidencia fragmentaria apunta claramente a importantes diferencias en el estilo, naturaleza, medida del tiempo y paso de los programas. Estas diferencias no parecen estar correlacionadas con la complejidad política del gobiemo o con los niveles de actuación de la macroeconomía de los países.

En cuanto al estilo, parecería que hay marcadas diferencias, por ejemplo, entre el programa evolutivo e internamente generado de los alemanes, el programa reformista y negociado de los franceses y españoles, y el radicalismo impuesto de los británicos. Las diferencias en la naturaleza de los programas se pueden ver en su espectro y composición. Como ya se ha reseñado anteriormente, los británicos han perseguido una estrategia de reforma de amplio espectro, y han buscado anclarlo en un grupo incluso más amplio, de racionalizaciones teóricas o ideológicas. Otros gobiemos (el de Lubber (1982-1986) en los Países Bajos, el de Olof Palme en Suecia, el de Rocard en Francia, el de González en España y el de Ciampi en Italia) han elaborado también programas de amplio espectro. En la mayoría de los otros países, sin embargo, el proceso de reforma ha sido limitado, esporádico y à la carte. No ha sido conducido por un nuevo paradigma o por una imperante necesidad, sino que ha sido reactivo, parcial y ampliamente instrumental.

Algunos países han compartido elementos del paquete británico. Otro no. Si los griegos en 1991 y 1992, y los italianos en 1993 se unieron a los británicos en tratar de modificar la influencia de los sindicatos (sobre acuerdos o sobre la financiación de sus actividades) sobre el sector público ${ }^{44}$, casi todos los demás no han tenido ni las ganas ni los medios de hacerlo. Otros programas de reforma tienen omisiones importantes o características distintivas en comparación con el británico. Así, los alemanes, griegos y portugueses, no han caído en la descentralización presupuestaria del tipo Next Steps. Los griegos, franceses y españoles han tratado de introducir más participación en ciertos niveles de la toma de decisiones, apenas una característica de las reformas británicas. Entre las características especificas de cada programa de reforma destacan la nueva Ley de Reclutamiento en Austria en 1989 (diseñada para despolitizar el sector público), el fortalecimiento del Tribunal de Cuentas en Italia (para combatir la corrupción), las importantes reformas en el sistema de justicia administrativa en Francia en los años 80, la creación de gabinetes ministeriales privados (o cabinets en el modelo francés), en Grecia, bajo el gobierno del Pasok, y el regreso en 1984 de la Administración pública española, que unió varios cuerpos administrativos, la decisión del gobierno portugués de facilitar dinero para programas avanzados de entrenamiento para sus gestores del sector público, tanto en instituciones nacionales como extranjeras.

Los diferentes estadios de los programas están claros si miramos a las políticas de presión a los recursos. Mientras que en Gran Bretaña la sfiestan se declaró «terminadan por un gobierno pre-laborista en 1979, en España, Portugal y Grecia, la ufiesta. siguió adelante hasta los tardíos años 80 o principios de los 90 (hubo un brusco aumento de gasto en los tres países durante el período de transición). Y mientras los países intentaban reducir o frenar el número de funcionarios desde el principio de los 80 , políticas similares se introdujeron tarde en países como Portugal ${ }^{45}$.

En cuanto al ritmo de las reformas, hay claras diferencias entre la locura mantenida del programa británico, y las actitudes esporádicas o cautas de la mayoría de los países europeos. Los italianos, tras un acercamiento aprensivo e incierto a la reforma, han decidido ahora seguir con una reforma comprensiva de la laberíntica, caótica y gigantesca Administración del país: el :pacchetto Cassese (nombrado tras un ministro reformador) contenía elementos enfocados a aumentar el control, la flexibilidad, la movilidad, la visibilidad y la responsabilidad de la actuación en la Administración pública y a eliminar o reducir la corrupción, el clientelismo, la promoción automática basada en la veteranía, el absentismo, los beneficios marginales y esos injustificadamente prolongados descansos para tomar café ${ }^{46}$. Sin embargo, la 
hostilidad burocrática, y la falta de coraje político están disolviendo la extensión de las reformas: una situación similar parece prevalecer en Espana. Este problema es todavía más grave con los griegos, quienes hacen ruidosas declaraciones de intentos (a menudo para satisfacer a la UE y a la OCDE), los cuales raramente se traducen en acción.

Las explicaciones para estas diferencias se encuentran en cuatro niveles interconectados: presiones; potencial; ambiciones; estructuras de oportunidades políticas percibidas.

Así como muchas presiones para la reforma han sido comunes, algunas se han diferenciado en su intensidad y en sus fases. Así, el Reino Unido sintió la presión presupuestaria antes que la mayoría de sus vecinos europeos. El ajuste administrativo a la Comunidad Europea fue, claramente, más exigente en los años 80 para los nuevos países miembros (España, Portugal y Grecia), que para los miembros fundadores. Más aún, algunos paises han sentido claramente diferentes presiones: la rápida federalización en Bélgica; el regionalismo en Italia y España ${ }^{47}$; la imperante necesidad de mejorar la calidad técnica de la gestión en Grecia (de ahí la creación de una Escuela Nacional de Administración en 1983 para oficiales de primera categońa) ${ }^{48}$ y Portugal; la simplificación del reentrenamiento de altos funcionarios de la Alemania del Este, y la absorción de los cinco nuevos Länder en Alemania ${ }^{49}$.

La despolitización ha sido un tema en Francia, y más especialmente en Italia (el 60\% de los funcionarios italianos han sido reclutados fuera del sistema de exámenes normal) y Grecia (donde un 15\% aproximadamente de los funcionarios han sido políticamente reclutados con contratos temporales). En estos dos últimos países se han tomado medidas para controlar los mecanismos de reclutamiento. Ambos países han tratado también de abolir la práctica de los funcionarios de poseer más de un puesto simultáneamente (en el caso de Grecia, dentro del sector público) ${ }^{\text {s0 }}$.

Los programas de reforma están también obviamente definidos por lo que es potencialmente reformable. Si no hay una radical privatización industrial en Suecia y en los Países Bajos, es porque ninguno de los paises ha tenido nunca un amplio sistema de empresas públicas. Similarmente, el potencial para la descentralización ha sido bastante mayor en Gran Bretaña, Portugal, Grecia y Francia que en Alemania o Dinamarca. Lo mismo puede decirse de la Administración pública. Así, los suecos y los daneses no han establecido numerosas agencias autónomas de los Next Steps, porque ya las tienen (y en cierto sentido fueron pioneros de su uso), y los alemanes, los daneses y los holandeses no han transferido actividades administrativas al tercer sector, porque ya las tienen.

Tercero, las diferencias de programas nacen, claramente, de diferentes ambiciones. Sería completamente erróneo interpretar la ausencia de programas radicales en la mayoría de los países como una indicación de falta de presión, potencial o voluntad política. Muchos países de la Europa occidental han definido simplemente ambiciones bastante limitadas, incluso cuando son aparentes las presiones para el cambio. Por ello, el gobierno alemán de Kohl, que ha caído sólo raramente (y hace poco) en un retórico antiestatalismo, o un -despedazamiento burocrático, se ha limitado únicamente a muy tímidas reformas de la Administración central. Y no aprovechó la oportunidad de la reunificación para la reorganización de las fronteras ni de los Länder de la Alemania del oeste ni del este (una política abogada por los reformistas que buscaban unidades territoriales más racionales). Sería igualmente erróneo ver a todos los programas radicales motivados por los mismos objetivos que aquéllos de los tatcherianos británicos del gobierno conservador danés de 1982. Los gobiernos de izquierdas en Espana, Francia y Suecia estaban empeñados en modernizar sus Administraciones públicas, no denigrarlas ni desmantelarlas 51 .

Finalmente, las diferencias entre los programas han sido determinadas claramente por estructuras de oportunidad de política doméstica. La voluntad y durabilidad política son vitales para reformar los gobiernos ${ }^{52}$, y estos ingredientes han estado frecuentemente en pequeñas reservas. De igual importancia es un ambiente político-institucional propicio. Un rápido análisis del programa de reforma británico subraya este punto, dado que todos los elementos eran favorables para hacer una política radical:

- Un fuerte liderazgo del ejecutivo articulado en torno a la figura del primer ministro. Este fue un factor en paises como los Países Bajos, y Dinamarca. Sin embargo, un Primer Ministro reformador está mucho más constreñido por sus colegas ministeriales, y ejercita muy poco o ningún mandato administrativo. En otros países, como por ejemplo Alemania, una aguda segmentación departamental o una compartamentalización impide los intentos para generalizar las propuestas de reforma en toda la Administración.

- El retroceso del gobiemo, del Parlamento y del partido mayoritario. De otra parte, la reticencia, las divisiones o la resistencia han sido frecuentemente el caso. Así, el gobierno alemán ha sido dividido por la privatización mientras que los Socialdemócratas suecos fueron profundamente divididos por la reforma del sector público ${ }^{53}$. Más aún, en el sistema británico la tradicional y estricta separación entre el personal político y el administrativo ha dejado al sector público sin protección ante las decisiones políticamente-impuestas. En muchos paises europeos, los funcionarios están poderosamente representados en el gobiemo, en el Parlamento y en los partidos políticos. 
- La ausencia de represiones constitucionales o estatutarias y un desarrollado análisis judicial. Este no es ciertamente, el caso de muchos países de la Europa occidental, donde las inhibiciones constitucionales son demasiado obvias (Alemania y Suiza, por ejemplo) o donde los jueces han puestos límites firmes en los reformadores (por ejemplo, el Tribunal Constitucional francés ha impuesto claramente obstáculos a la privatización de ciertos servicios de bienestar y de servicios penitenciarios). Alternativamente, hay leyes sobre la función pública que limitan efectivamente las ambiciones de reforma. Este es el caso en Francia, Alemania, Italia, Austria y Bélgica. Quizás, más profundamente, el sector público en el Reino Unido, a diferencia que en cualquier otro lugar, no recibe ningún escudo cultural en la forma de una desarrollada doctrina del Estado, y su irreducible e inalterable esencia y función: no hay ningún equivalente en Gran Bretaña, por ejemplo, para los principios constitucionales alemanes del Sozialstaat o del Estado federal que coloca eficazmente límites en las ambiciones de los reformadores. La historia del Reino Unido ha llevado a una identificación del gobierno con el Estado, a una profunda aceptación de la soberanía parlamentaria y a un "prejuicio ejecutivo" —una aceptación instintiva por la mayoría de las élites- de que el interés de un gobierno, respaldado por el Parlamento, coincide con el del Estado. Los Estados con las historias más turbulentas han erigido barreras constitucionales o culturales contra tales nociones.

- La ausencia de las poderosas represiones políticas generalizadas que aminoran o incluso previenen programas particulares. Por supuesto, las represiones políticas han existido en el Reino Unido, e incluso la Primera Ministra Thatcher era ocasionalmente, muy sensible a ellos: la privatización de la provisión estatal de bienestar siempre fue manejada con delicadeza, y el gasto público en algunas áreas incluso aumentó en términos reales por razones políticas. Sin embargo, los conservadores británicos no fueron confrontados con el inherentemente costoso o inhibidor proceso de transición política donde hay una primacía de políticas" (España, Portugal, Grecia) o de reconstrucción territorial (Alemania o incluso Bélgica), o de modos de hacer política persistentemente consensuales, aunque erosionados (los Países Bajos, Alemania, Dinamarca, Suecia) ${ }^{54}$.

- Una buena voluntad y capacidad de reestructurar las redes políticas que protegían al sistema tradicional o marginalizaban a aquellos que se oponían a la reforma (incluyendo, no sólo a los sindicatos, sino también a los gestores mal dispuestos e incluso a la dirección de la Función Pública!). De otra parte, con una o dos excepciones (por ejemplo, Italia desde el final de 1992), se ha hecho un intento de evitar la compulsión, y de negociar el proceso de reforma con los gestores del sector público o con los sindicatos: éste es el caso en Francia donde el acuerdo sindicalista ha sido necesario para ciertos temas, en España, Irlanda, Bélgica, Grecia; Alemania y Suecia, donde los sindicatos y los gestores han estado a menudo íntimamente involucrados en las negociaciones de reforma. En España, por ejemplo, el paquete de reformas de 1988 se discutió ampliamente: entre 1989 y 1991 más de 1.500 personas fueron consultadas, y entonces fue introducido un plan piloto, y se firmó un acuerdo para modernizar la Administración, en noviembre de 1991, entre los representantes de los cuatro sindicatos importantes y el gobierno del PSOE. En Francia, el gobierno de Rocard, desde septiembre de 1989, siguiendo sus ambiciones de reforma decidió sobre un vasto programa de consulta. Organizó 29 coloquios regionales y una gigantesca reunión en París en noviembre de 1990 .

- La falta de una efectiva oposición politica, que fue el caso del Reino Unido en los años 80. Sin embargo, éste no ha sido el caso en muchos otros países con gobiernos Conservadores. Así, el gobierno Liberal Conservador, elegido en 1982 en Dinamarca se vio obligado a retirar sus planes para contratar una gama de actividades siguiendo a las efectivas oposiciones de los socialdemócratas en el Parlamento respaldados por los sindicatos del sector público ${ }^{55}$.

- La babilidad de movilizar personas capaces que ocupen situaciones ventajosas para ayudar al programa de reforma. Contrariamente a lo que se esperaba, muchos funcionarios se han manifestado sensibles a la necesidad de reforma $-\mathrm{y}$, en algunos casos-, se han convertido in cluso en el motor de la reforma (notablemente en Gran Bretaña y Francia). Sin embargo, en muchos países (incluyendo a Austria, España, Italia y Grecia) los reformistas (a menudo tecnócratas) se han encontrado con la indiferencia, aprensión e incluso hostilidad de sus colegas. Efectivamente, la tradición legal y la cultura burocrática permanece atrincherada en muchas administraciones: frecuentemente, no hay nadie disponible para gestionar el tipo de reforma ${ }^{56}$ lo cual pone en entredicho la ideología operativa del Rechtsstaat ${ }^{57}$.

- La construcción de un discurso legitimador que ha tomado una forma negativa (gobierno anti-grande, burócratas anti-remotos y libertinos, antiestatales) o que ha sido más positivo en el tono: la privatización y comercialización en nombre de la opción individual; la entre- 
ga de autoridad a organizaciones del tercer sector en nombre de una fortalecida sociedad civil; la introducción de nueva tecnología en nombre de la modemización; - y la descentralización de la discrecionalidad presupuestaria a agencias en nombre de la eficiencia. La eficiencia. ha sido a menudo invocada para avanzar a través de reformas específicas, por muchos gobiernos; mientras que los gobiernos socialistas español y francés han desarrollado una ideología de modernización para justificar sus programas. Sin embargo, sólo los conservadores noruegos y daneses han adoptado una estrategia ideológica multi-pronged británica para atacar al sector público a fin de legitimar sus planes para reformarlo. La mayoría de los gobiernos europeos, a través del deseo o de la prudencia, no han intentado perseguir sus limitados, pragmáticos y negociados programas en términos ideológicos.

Los diferentes programas están, por lo tanto, enraizados en la diferente intensidad y temporalidad de presiones similares, presiones diferentes, motivos, capacidad constitucional, políica e institucional, represiones y voluntad, y en la compleja relación entre estos factores. Cada país de la Europa occidental tiene una mezcla única de factores que explican una persistente diferencia, a pesar de la clara evidencia de convergencia. En resumen, los contextos nacionales importan.

\section{La reforma del sector} público: impacto, límites, dilemas, paradojas y problemas

¿Qué dibujo emerge de este breve resumen de los diferentes programas de reforma del sector público? La falta de datos sistemáticos, particularmente sobre la implementación e impacto de los distintos programas de reforma, hace muy dificil una comparación significativa, sin embargo, pueden discernirse, claramente, ciertas líneas generales.

En primer lugar, la reforma del sector público está en la agenda política de todos los gobiemos de la Europa occidental, y la naturaleza de los programas de reforma ha ampliado su espectro en muchos países, y han sido radicalizados en su naturaleza en varios. Se podría argumentar, como se ha reseñado anteriormente, que la reforma del sector público avanza en algunos países (como Suecia y el Reino Unido) desde ser una ac- tividad ad boc a ser una "política pública. generalizada. Segundo, bajo el impacto de presiones convergentes, muchas políticas similares están siendo implementadas -a pesar de las diferencias en las fases, el ritmo, y el estilo de la implementación-. Tales políticas incluyen intentos de estabilizar el tamaño del sector público y los salarios de sus funcionarios, de privatización en sus distintas formas, de mayor transparencia, de creación de nuevos cuerpos, y de introducción de nuevas tecnologías. Tercero, el duradero significado de los distintos contextos nacionales puede verse en la amezcla política. que se ha adoptado: el Reino Unido ha sido un activo privatizador, pero, no por ello un menos activo centralizador. Francia ha privatizado, pero también descentralizado, España ha descentralizado radicalmente, pero ha privatizado relativamente poco. La nueva gestión pública ha afectado a algunos países, especialmente al Reino Unido, pero a otros no, como por ejemplo Alemania.

En términos generales, la actual situación del sector público puede describirse en términos de la siguiente inventada aliteración. En comparación con el principio de los años 80 , se está convirtiendo en:

- más definido, como los hacedores de política nacional (ayudados u obstaculizados por los tribunales) buscan el Santo Grial -el irreductible núcleo del Estado-, y ajustar la Administración al servicio de ese meollo;

- más disminuido en su papel y prestigio, sino siempre en tamaño (el cual, a pesar de todas sus ambiciones reformistas, permanece obstinadamente estable y alto);

- más decreciente en muchos de sus imperativos: incrementalismo automático y reconfortante, basado en la acomodación política y social ha dado paso a una mayor prudencia y disciplina presupuestaria;

- más dividido como resultado de una crecida competencia interna por los recursos;

- más desagregado o fragmentado como consecuencia de la descentralización, desconcentración y difusión;

- más distante del ciudadano porque la implementación está siendo transferida cada vez más a agentes no-estatales;

- más desregulado en una gran variedad de formas;

- más desnacionalizado, como resultado de una globalización y regionalización;

- más defensivo y desmoralizado, desde que es objeto de una incesante crítica, siendo equivocamente tomado como la causa y no como el síntoma de los defectos del sistema al que sirve, y desde que es el objeto de reforma de los políticos, los cuales son insensibles a los 
escondidos costes a largo plazo de una moral en colapso ${ }^{\text {is. }}$.

Más importante, el sector público parece estar más desorientado, o libre de tensión ${ }^{\not}$, con la aparente destrucción de muchas de las propuestas del sistema tradicional. Estas propuestas eran: un servicio público basado en el Estado nacional; un énfasis en el tamaño para asegurar las economías de escala, y en planificar (de ahí la integración de compra y aprovisionamiento); unas extensas líneas jerárquicas, con reglas detalladas para gobernar los niveles de jerarquía; una aplicación de una regla legal como modo operante dominante, con servicios supuestamente eficientes si fueran aportados, en un modo uniforme, de acuerdo a la ley; un funcionariado permanente y a tiempo completo el servicio del gobiemo es una carrera; un trabajo organizado de acuerdo a reglas generales de una naturaleza impersonal-, para garantizar una igualdad (incluyendo los salarios) entre gente del mismo rango; una distinción entre la administración y la realización de política, basada en la lealtad a los amos políticos y la neutralidad política de los funcionarios; una separación clara de los ámbitos públicos y privados; el anonimato de los funcionarios públicos; una especialización funcional; un rasgo distintivo generalizado imbuido con nociones de interés público", «equidad», ajusticia» y suniformidad.

Aunque, desde luego, este desmantelamiento del sistema tradicional no debería ser exagerado. Primero, el tradicional modelo weberiano era el tipo ideal (como WeBER aclara) y muchas de sus características, en varios países, eran o ficticias o estaban totalmente ausentes. Sin embargo, en otros paises siguieron siendo importantes, y en muchos proporcionaron un entramado normativo ${ }^{60}$. Segundo, como se ha reseñado más arriba, algunos gobiernos (especialmente el alemán y el belga) incluso cuando se han visto confrontados con grandes presiones, no han hecho ningún intento significàtivo de alterar el funcionamiento interno de sus sistemas existentes ${ }^{61}$. Tercero, las experiencias pasadas nos han enseñado a ser escépticos acerca del impacto de los programas de reforma en el sector público, que tiene una distinguida fama de enterrar las ambiciones de los políticos ${ }^{62}$. Las rigideces constitucionales e institucionales, así como la falta de una voluntad política mantenida, suelen diluir el impacto de las reformas ${ }^{63}$. Por ejemplo, las tradiciones de decisiones centralizadas, a menudo apoyadas en el Ministerio de Hacienda, o en el ministro patrocinador, obstaculizan la búsqueda de una mayor autonomía interna ${ }^{64}$.

Así, en el Reino Unido, se espera de alos nuevos gestores públicos" que desarrollen una cultura empresarial en los servicios públicos, y que se enfoquen hacia las salidas y los servicios de reparto -pero dentro de un sistema de gasto público dominado por los beneficios y por la limitación de dinero líquido-, con una fuerte tradición de control del Ministerio de Hacienda. Más aún, siguen empantanados con circulares y regulaciones, y raramente tienen derecho a reclutar, entrenar, promover o despedir al personal que trabaja para ellos.

Más profundamente, sabemos muy poco sobre el impacto de los distintos programas de reforma sobre la cultura del funcionario público ${ }^{65}$. La evidencia fragmentada solamente refuerza un escepticismo natural: así, en Gran Bretaña y Francia las poderosas peticiones para la innovación de calidad, la comercialización y una nueva gestión participatoria, no parece afectar a esos funcionarios de alto rango que hacen las peticiones ${ }^{66}$; la extendida tecnología de información al sector público sigue más limitada de lo que sus defensores creen ${ }^{67}$. Así, a pesar de los cambios y adaptaciones del período desde el principio de los años 80, el modelo tradicional de Administración progresiva sigue intacto en muchas de sus características esenciales. No obstante, el proceso de reforma y adaptación tuvo su impacto, y ha arrojado un dilema central y varias paradojas.

El dilema central para los reformadores puede afirmarse simplemente: las reformas efectivas deben, generalmente, atraer el apoyo de aquéllos a los que afecta, pero muchos de esos afectados son alérgicos $u$ hostiles a las reformas. La negociación conlleva, invariablemente, la modificación y dilución, mientras que la imposición corre el riesgo de desmoralizar y de motivar a aquellos implicados en la implementación.

Las paradojas abundan. La primera gran paradoja es que los programas de reforma más radicales parecen haber sido introducidos en jlos países a los que menos falta les hace! Los países con la mayor necesidad (la diplomacia prohíbe mencionarlos en este artículo) tienen o pocas ambiciones de reforma, o programas de reforma inadecuados.

Paradoja número dos: muchas de las reformas están inspiradas en las teorías o modelos de la gestión privada, lo cual es notoriamente inconsistente; tienen la vida media de una heroína en una ópera de Puccini. Más aún, la reputación de la gestión privada en el país con la mayor tendencia de emular al sector privado, el Reino Unido, está, al menos, comprobada. Por otra parte, en Alemania, donde la gestión privada tiene una imagen envidiable, hay pocas presiones en la Administración pública para imitarla. En cualquier caso, ya parece hora de que los especialistas de la Administración pública tengan una visión más crítica a la debilidad y a los problemas de la gestión del sector privado, en vez de limitar sus análisis a los problemas de trasplante a la Administración pública de un idealizado y mal entendido modelo privado.

La tercera paradoja tiene que ver con el papel de los más attos burócratas como uno de los principales motores de la reforma. En mucha de la literatura neoliberal o de elección pública, la cual ha supuesto mucha munición intelectual para los reformadores políticos, estos burócratas son tachados de intrínsecamente ineficientes, obteniendo satisfacción en el trabajo del 
politiqueo, su status y gozar de pensiones garantizadas. Están unidas a la inercia y satisfechos con aplicar las reglas. O, por supuesto, están muy interesados en la maximización del presupuesto o en la expansión de la agencia. O, según otra escuela de elección pública, están encajados en las grandes ‘coaliciones distribucionales" -esas redes cómodas y conniventes tan culpables de expandir el Estado y de minar su competitividad- Históricamente, ésta fue siempre una caricatura aunque haya alguna evidencia empírica, anecdótica en algunos países que proporciona un parecido a la verdad con la descripción. Hay también bastante evidencia histórica de que muchos de estos muy criticados burócratas, fueron, a menudo, la fuente de efectivas iniciativas de reforma. Acercándonos más al argumento, la evidencia actual sugiere que los altos burócratas no son todos alérgicos a los programas de reforma - los cuales, en general, impactan más fuertemente en los rangos más bajos-, y los cuales a menudo ofrecen oportunidades más excitantes de gerencia políticamente orientada. ¿Por qué malgastar tu vida voceando "Si, Ministro" cuando hay un espacio para la autonomía?

La cuarta paradoja es que mientras muchas de las reformas son diseñadas para eliminar costes, el resultado final de algunas de ellas puede ser el opuesto. Tomemos como ejemplo la evaluación, una locura actual que tiende a ignorar el coste del potencial humano involucrado en el proceso. La evaluación puede identificar áreas de desperdicio. Pero también tiende a revelar las disparidades no sólo en la actuación, sino también en los resultados: parte de la población está siendo relativamente maltratada. Estas disparidades estaban escondidas previamente. El resultado será la creación de presiones políticas para allanar tales disparidades. Más profundamente, la transformación de ciudadanos en clientes o compradores, con derechos claramente definidos fijados por los objetivos, puede tener el efecto de mejorar la calidad. Pero está también creando anticipaciones y presiones para remediarlo - a menudo de naturaleza legal-. No se necesita un conocimiento profético para predecir que una cara litigación será una de las consecuencias del actual programa de reforma. Efectivamente, está encajado en la misma lógica del programa. Similarmente, la claridad o transparencia - aparentemente objetos deseables por sí mismos- podrían tener costes escondidos no deseados y no sólo organizativos. Mucha de la política pública trata sobre el racionamiento, sobre la distribución de los escasos recursos, sobre juegos de suma cero y costes de oportunidad. Para que el racionamiento funcione en un espacio de tiempo debe, o ser ignorado a través de los mercados negros, $u$ ofuscado o debe ser legitimado. Es una tarea intrínsecamente dificil de sobrellevar por una sociedad democrática en tiempos de paz y en períodos de estancamiento o recesión. En general, el racionamiento desde la guerra ha sido razonablemente bien gestionado por una combinación de ignorancia, ofuscación y legitimación. Sin embargo, algunas de las actuales reformas, conducidas con buenas intenciones parecen diseña- das para minar las tres propuestas esenciales: la ignorancia está siendo sustituida por derechos definidos y la ofuscación por la transparencia. Aún más significativa es la deslegitimación del proceso -las decisiones sobre el racionamiento están siendo suprimidas de los políticos y las profesiones autorreguladas, como profesores y doctores, y están siendo transferidas a gestores y a empresarios dirigidos por una explícita lógica de mercado- simplemente les falta la legitimidad esencial para extender la miseria esencial. Podemos, entonces, esperar mayores controversias y recursos a los tribunales para remediarlo, acentuando así la tendencia hacia la litigación. En resumen, las ventajas presupuestarias de muchas de las actuales reformas son de corto plazo.

El tema de la claridad y la transparencia, que acaba de ser sacado a colación, conlleva todavía otra paradoja paradoja número cinco, como se ha señalado, esa transparencia, traducida en claras metas $u$ objetivos gerenciales, y combinados con una creciente autonomía gerencial, está llevando a una mayor ofuscación, y no el tipo de ofuscación que es deseable. Es una ofuscación en relación a la responsabilidad politica que es ya, de por sí, dificil de establecer. El problema se empeora por las tendencias actuales. Sin embargo, es muy crítico con la democracia política. Combinada con otras tendencias, la gerencia nubla aún más las líneas de responsabilidad. Puede ser conveniente para los políticos esconderse tras la pantalla de humo de la discrecionalidad y autonomía gerencial, en la Administración pública, pero no añade mucho a la calidad democrática de la toma de decisiones - como se ha subrayado en varios casos- recientes en Gran Bretaña.

La sexta paradoja implica a la eficiencia, el Santo Grial de los reformadores administrativos. Uno puede argumentar, con cierta justificación, que uno de los logros principales de los actuales programas de reforma es sensibilizar a los funcionarios de todos los niveles de la Administración pública en el valor de la eficiencia, no importa lo vagamente entendido que esté. Y parece muy deseable y perfectamente legítimo definir el criterio para la eficiencia. De todas formas, no requiere mucha sofisticación el darse cuenta de que tal ejercicio está cargado de significado político, dado que la eficiencia en la entrega de bienes públicos, conlleva complejas percepciones externas políticas y sociales. No vendemos simplemente una desagregada gama de productos como detergente y patatas. Estamos haciendo malabares con múltiples requerimientos interconectados y a menudo conflictivos o nebulosos. Acercándonos más al argumento, en términos de la paradoja de la eficiencia, la cuestión es si la eficiencia va a ser maximizada, sistemáticamente denigrando y abiertamente despreciando los rasgos distintivos y las éticas del servicio público, e introduciendo toda una gama de medidas que desmoralizan y desmotivan a aquellos que sostienen y defienden los principios del bien público. Si los ciudadanos se transformaran 
en clientes, también transformaríamos lentamente a los funcionarios públicos en productores, motivados por la lógica y por las recompensas del mercado privado. $Y$ en esas circunstancias, muchos funcionarios que trabajan duro y están mal pagados, conducidos previamente por un compromiso con el bien público, exjgirán una remuneración adecuada: si la reciben, los costes crecerán: si no -el caso más probable - no tendrán un gran incentivo para dar lo mejor de ellos mismos. En ese sentido, la destrucción de los rasgos distintivos públicos es profundamente ineficiente -aunque los resultados tarden un poco en emerger-.

La penúltima paradoja está basada en la ambición de los reformadores de reducir el papel del Estado. No obstante, los programas radicales de reforma diseñados para producir un retraimiento del Estado, requieren un Estado fuerte para iniciar e implementarlos; ésta es una paradoja familiar y puede observarse en otros programas de reforma radical. En segundo lugar, varias de las reformas conllevaron una crecida actividad estatal -como podrá atestiguar cualquiera que tenga la desgracia de ser un doctor, maestro o profesor de universidad británico- Los cuerpos, que habian sido ampliamente autogobemados anteriormente, han sido embestidos por los ejercicios de evaluación, los indicadores de actuación y las metas y toda la demás parafernalia de un Estado intervencionista.

Finalmente, es seguramente paradójico que muchos de los cuerpos -internacionales y nacionales- que están tan empeñados en la evaluación para la eficiencia y la calidad del empresario gerencial no parezcan muy dispuestos a poner en práctica lo que predican.

En resumen, el proceso de modemización administrativa ha generado una serie de paradojas que tienden a confirmar la sentencia de la vieja política pública, de que las soluciones de hoy, son los problemas de mañana. Afortunadamente, al menos una de estas paradojas puede ser de naturaleza transitoria, algunas son específicas del país, y otras pueden ser más aparentes que reales. Altemativamente, pueden ser explicadas por un desplazamiento político, o por las impredecibles consecuencias de algunas reformas, aunque la mayoría de los resultados impredecibles eran perfectamente predecibles.

Sin embargo, algunas de las paradojas principales, con sus indeseables implicaciones a medio o corto plazo, parecen tener un carácter general y permanente. Éstos parecen estar basados en la disensión, en las contradicciones políticas que caracterizan a las reformas, y en la inocencia de los mismos reformadores. La ignorancia, simulada o real, es más manifiesta acerca de las necesidades de una sociedad democrática con sus desordenados trade offs, con su constante necesidad de equilibrar la balanza de las contradicciones inherentes, con sus requerimientos de equidad y legitimidad. También hay ignorancia, acerca de la verdadera naturaleza de las burocracias públicas, que raramente funcionan según las premisas a priori de una teoría. Las contra- dicciones políticas son demasiado numerosas para ser exploradas, pero esencialmente, surgen de las conflictivas fuentes ideológicas y ambiciones de los reformadores. Finalmente, hay una ingenuidad -inocencia acerca de la naturaleza del sector privado, así como la naturaleza del mercado- los adorados modelos sobre los cuales están fundamentadas muchas de la reformas. $\mathrm{Si}$ comparamos una óptica idealizada del sector privado y los trabajos del mercado con una percepción mal intencionada del sector público, no es sorprendente que surjan las demandas de reforma. Una óptica más medida de ambas nos llevaría a la prudencia.

\section{Redefinición del aparato del Estado: algunos comentarios finales}

No hay nada nuevo acerca de las reformas y los cambios en los sectores públicos de la Europa occidental, bien impuestas externamente o como resultado de un ajuste interno a las circunstancias $^{68}$. Y la actual ola de reforma no está, en modo alguno, confinada a la Europa occidental. Además, como hemos visto, la intensidad, las fases y el ritmo de las reformas han variado a lo largo y ancho de la Europa occidental. Y las variaciones pueden explicarse por la naturaleza del sector público a reformar, por el compromiso político y por la durabilidad de los reformadores y las estructuras políticas de oportunidad en las que se encuentran. Varios países, debido a una falta de necesidad, falta de ambición, falta de medios o falta de voluntad han perseguido unas estrategias de reforma muy moderada, incrementales y negociadas. Sin embargo, hay aspectos de los actuales programas de reforma en varios países de la Europa occidental, que parecen reflejar una seria pregunta de las bases de sus sistemas tradicionales del sector público.

Los observadores se han referido al movimiento hacia "el Estado desinversor. (con la privatización y desregulación), «el Estado frugal. (con el retraimiento presupuestario y rigor), eel Estado estratégicon (con una retirada de las ppolíticas públicas), el Estado capaz (que asegura una provisión, más que proveer directamente), el Estado evaluatorio (con la multiplicación de nuevos cuerpos, mecanismos y criterios de evaluación), ael Estado regulatorion (con la proliferación de nuevas agencias regulatorias), el Estado hibrido (con las crecientes interpenetraciones de las esferas pública y privada), y el Estado supermercado (sun proveedor de servicios, un epifenómeno de fuerzas tecnológicas, económicas, demográficas y físicas fuera del explícito control de cualquier actor", basado en la corporación de negocios y en la que las pala- 
bras claves son supervivencia, flexibilidad, economía y eficien(ia) ${ }^{69}$. Ciertamente podemos ver elementos de todos estos cambios -no son mutuamente excluyentes - con mezclas variadas de país a país. Más aún, la abstención del Estado tiende a compensarse, o a quedar neutralizada, por la expansión estatal. por otro lado.

El estudio de la reforma radical del sector público -espejo y motor de las reformas - tiende a revelar incoherencias, contradicciones y costos ocultos. También subraya los límites a la redefinición del Estado en una forma minimalista y puramente privada de mercado. Y no sólo por los impedimentos políticos o constitucionales. El problema reside en la propia naturaleza del Estado. Los mercados pueden ser útiles para asegurar que los productores no sean dominantes y que se tengan en cuenta a los consumidores, e incluso, si la situación lo permite, asegurar algún grado de eficiencia. El Estado, con su énfasis sobre la planificación y sus extensas estructuras jerárquicas, puede no ser eficiente ni sensible a las demandas, pero sustituir las jerarquías por mercados" (tomando prestada la frase de Williamson) es un proceso lleno de dificultades.

Lo mismo se puede decir de la privatización extensa del Estado y por las mismas razones. El contexto del Estado es la democracia, el Rechstaat, con el gobierno tomando decisiones autoritarias al mismo tiempo que se ocupa de la gestión de las macro externalidades, asegurando la igualdad y la responsabilidad, y con una base organizativa enraizada en los valores de la imparcialidad, objetividad, regularidad, predictabilidad, legalidad y legitimidad ${ }^{70}$. El sector público, con el principal instrumento del Estado, funciona de acuerdo a normas que derivan de muchas, y a veces contradictorias, racionalidades: política, legal, institucional, técnica, social y económica, y una gran parte de su lógica exige alguna forma de weberianismo, con énfasis en la uniformidad, la imparcialidad, el anonimato y las normas jurídicas.

Mientras que es altamente positivo hacer al gobierno más parecido al mundo de los negocios, es altamente problemático hacer que funcione como una empresa (business-like vs. like business). El sector público siempre tuvo que hacer juegos malabares con conjuntos de valores en conflicto, incluyendo la democracia (por ello, la responsabilidad políica), la equidad (que implica uniformidad) y eficiencia (mínimos costos) ${ }^{71}$. Mucha de la actual política radical de reforma del sector público está obsesionada con la eficiencia, en sentido estricto, y basada en una visión simplista de la burocracia, una visión naive del mercado, una opinión idealizada del sector privado, una insensibilidad de los costos no previstos de la reforma, un exceso de optimismo acerca de los resultados prácti$\cos y$, quizás más importante, una visión equivocada del Estado.

\section{Lecturas adicionales}

La reforma administrativa ha generado una amplia literatura. Además de las obras citadas en las notas de esta contribución, ver, por los datos comparativos, el informe anual de la OCDE, Public Management Development (París: OCDE); Naciones Unidas, Selected Studies on Major Reforms (NY: UN, 1988); El anual Annuaire Européen d'Administration Publique (una de las mejores fuentes); Sabino CASSESE y Claudio Franchinl (eds.), Tendenze Recenti della Riforma Amministrativa in Europa, (Bologna: Il Mulino, 1989); L.J. RoBORG, R.R. STOUGH, Th. TooNEN (eds.), Public Infraestructure Redefined (Leiden: Groen, 1988); Gerald E. CAIDEN (ed.), Administrative Reform Comes of Age (Berlin: De Gruyter, 1991); Joan CORKery (ed.), The Implications for Public Administration of the Changing Role of the State (Brussles: ILAS, 1991); edición especial del International Review of Administrative Science, Vol. 57, 1991, editado por Kenneth Kernaghan, Gary Warmsley et al. (eds.), Refounding Public Administration (London: Sage, 1990); Yves MÉNY y Vincent WRIGHT (eds.), La Riforma dell'amministrazione in Europa (Bologna: Il Mulino, 1994); Christopher PolutT, Managerialism and the Public Services: The Anglo-American Experience (Oxford: Basil Blackwell, 1990); James RadCufF, The Reorganisation of British Central Government (Aldershot: Dartmouth, 1991); Ian TAYLOR y George PopHam (eds.), An Introduction to Public Sector Management (London: Unwin Hyman, 1989); Owen E. Hughes, Public Management and Administration (London: MacMillan Press, 1994); Bruno DenTE et al., Riformare la Pubblica Amministrazione, (Torino: Agnelli, 1995); Hans A.G.M. BECKE et al., Civil Service Systems in Comparative Perspective (Bloomington: Indiana University Press, 1996).
Articulo traducido por Laura ALBA MUNOZ.

- Nuffield College. Oxford (Reino Unido).

' V. WRIGHT, .Public Administration, Regulation, Deregulation and Reregulation. en Kyell A. Ellassen y Jan KoOLMav, Managing Public Onganizations: Lesson from Contemporary European Experience London, Sage 1993, págs. 252-253.

\footnotetext{
' Sabino CASSESE (ed.), The European Administration, Brussels, ILAS, 1987.

" Ver, por ejemplo, M. KeAting y B. Jones, Regions in the European Community, Oxford, Clarendon Press, 1985.

' Ver, por ejemplo, Conseil Economique et Social, La Modermisation de l'Administration, Paris, 1989.
} 
' Para una críica de estas teorías ver Peter Sel, Government by tbe Martet? Tbe Politics of Public Cboice, London, MacMillan Press, 1993.

- Pierte BOURETz y Evelyne PISIER, Le paradore du fonctionnaire, Paris, Calman-Lévy, 1988.

Ver por ejemplo Philip COOPER, Protecting the environment and its administrative implications, trabajo inédito, Congreso anual del IIAS, Viena, 1992.

8 Jean Paul BAQuinST, Administrative Modernization and New Technologies in France, Intemational Review of Administrative Sciences, vol. 33, 1957, págs. 171-182.

9 Calliope SPANOU, Fonctionnaires et Militants: étude des rapponts entre l'administration et le nouveaux mouvements sociaux, Paris, L'Harmatten, 1991; M. BARZELAY, Breaking Tbrougb Bureaucracy, Berkeley, University of Califomia Press, 1992.

in Ver, por ejemplo, Roben Lo:v, L'État Passion, Paris, Plon, 1992.

"David Osborve y Ted GafBler, Reinuenting Government, New York, Addison-Wesley, 1992.

1: Richard MURRAY y Claes ÖRTENDAHL, •A Market-Oriented Administration in the Welfare State: Swedish Efforts to Find a New Way, en Naciones Unidas, Selected Studies on Major Administrative Reforms, New York, 1985, págs. 52-53.

1.5 La literatura sobre la Nueva Gestión Pública es amplia. Ver, en especial, Andrew HEDE, -Trends in the Higher Civil Services of Anglo-American Systems, Governance, Vol. 4 (4), octubre 1991, págs. 489-510.

"Ver, por ejemplo, Marie-Christine KESSLER, -Un Paradoxe: Les Reforms Administratives à l'étranger, trabajo inédito, Congreso anual ILAS, Viena, 1992.

is Sobre el tema del aprendizaje, ver Franz-Xavier Kaufmavs, Giandomenico Majone y Vincent Osтrom, Guidance, Control and Evaluation within the Public Sector, Berlin, De Gruyter, 1985

I" C. LESQUESNE, L'adaption des ministères techniques à l'existence des Communautés européennes: le cas de l'administration française, Revue Administrative, 1988, págs. 566-572; Charles DEBBASCH (ed.), Administrations Nationales et Integration euro péenne, Paris, CNRS, 1987; IIAS, The Administrative Implications of Regional Economic Integration: The Case of the European Community, Brussels, 1991; Claudio FRanCHIN], Administrazione Italiana e Administrazione Communitaria, Roma, Cedam, 1992; Sabino CASSESE (ed.), The European Administration, Brussels, IIAS, 1980

1i Administration et nouvelles technologies de l'information, une necéssaire adaptation du droit, Paris, Documentation Française, 1988; John A. TaYIOR y Howard W1. WaMS, Public Administration and the Information Policy., Public Administration, Vol. 69, verano 1991 , págs. 171-190.

${ }^{18}$ Jean Paul Costa e Yves JEGouzo, L'Administration Française face aux défis de la décentralisation, Paris, Editions STH, 1988

19 James G. MARCH y Johan P. OLSEN, Rediscovering Institutions. The Organizational Basis of Politics, New York, Free Press, 1989.

3) Ver la bibliografia extensa y Hans-Ulrich DeRIJEv, Observations on the State of Comparative Administration Research in Europe, Governance, 513, julio 1992, págs. 279-311.

"I Jonathan Sмгтн y David Gould, Civil Senvice Numbers, London, European Policy Forum, 1993

" Andrew DunsiRe y Christopher HOOD, Cutback Management in Public Bureaucracies, Cambrige, CUP, 1989.

$"$ Vincent WRGHT (ed.), Industrial Privatization in Western Europe, London, Pinter Publisher, 1994.

$\therefore$ Julian LE GRand y Ray Robinson (eds.), Privatization and the Welfare State, Londres, George Allen \& Unwin, 1984; Ray ForRest y Allan MURIE, Selling the Welfare State: the Privatization of Public Housing, Londres, Routledge, 1991; P. TAYLOR-GOOBY y R. LAwson (eds.), Markets and Managers: New Issues in the Delivery of IVelfare, Buckingham, Open University Press, 1993

i Claude Alber ColliarD y Gerard Timstr, Les autorités administratives independantes, Paris, PUF, 1988; Jacques CHEVAUER, Le autorità administrative independenti, Roma, Cappelli, 1986.

* Wolfgang STREEK y Philippe SCHMTTER (eds.), Private Interest Government, Londres, Sage, 1985; Helmut K. ANHEIER y Wolfgang SEIDEL (eds.), The Third Sector. Comparative Studies of Nonprofit Organizations, Berlin, De Gruyter, 1990; Tore MODEEN y Allan Rosas (eds.), Indirect Public Administration in Fourteen Countries, Helsinki, Abo Akademis Förlag, 1988. $\ulcorner$ Domald Ketne, Goueniment by Praxy: Managing Federal Programmes, Washington D.C., Congressional Quanterty Press, 1988.

- Tore MODEEv y Altan ROSAs (eds.), Indirect Public Administration in tbe Fields or Education and Progress, Helsinki, Abo Akademis Förtag, 1990.

9 John J. GLrvy, Public Sector Financial Control and Accounting, Oxford, Basil Blackwell, 1987; Henrik NEPPER-CHRISTENSEv, .The Financial Management System of the Danish National Labor Inspection, International Review of Administrative Sciences, Vol. 54, 1988, págs. 233-246; Christian de VISSCHER, -The Modemization of Budgetary Techniques and Financial Control, International Review of Administrative Sciences, Vol. 55, 1989, págs. 323-364.

". Eric Monvier, Evaluation de l'action des pouvoirs publics, Paris, Economica, 1992 Patrice Durav y Eric Monvier, -Le développement de l'évaluation en France; nécessités tecniques et exigences politiques, Rerre Franfaise de Science Politique, Vol. 42, 1992, págs. 23j-261.

"1) Ver, por ejemplo, Howard DAVES, Fighting Leviatban: Building Social Markets that Works, London, Social Market Foundation, 1992

:? El mejor análisis de la Nueva Gestión Pública lo aporta Christopher Hood, nota 43. Ver también la contribución de George JonES en Y. MÉNYY y V. WRIGHT, La Rifor ma dell'administrazione in Europa, Bolonia, II Mulino, 1994; Spencer ZrFCAk, New Managerialism: Administrative Reform in Whitehall and Canberra, Buckingham, Open UP, 1993.

"Hay una extensa literatura en Next Steps. Ver, por ejemplo, Next Steps for the British Civil Service, Governance 3/2, abril 1990, págs. 186-96; Patricia GREER, Transforming Central Government. The Next Steps Iniatiative, Buckingham, Open UP, 1994.

${ }^{4}$ Ver, por ejemplo, Abraham VERMEULEN, contract Management in the Netherlands, Intermational Review of Administrative Science, Vol. 54, 1988, págs. 201-17.

3: Financial Times, 8 de marzo, 1994.

- A. GuULÉn y E. RaMrRez de Prado, •Administración por objetivos, Documentación Administrativa, n. ${ }^{\circ} 223,1991$, págs. 139-204.

"Florence MaSA, Gestion privée pour services publics, Paris, Inter Editions, 1990.

* Nicole DE MONIRICHER, Lla fonction publique de carrière en France: problèmes et perspectives, Revue Internationale des Sciences Administratives, 57/3, 1991, págs. 433-4.

") Independent, 23 de noviembre de 1993.

*) Céline WIENER (ed.), L'ézolution des rapports entre l'administration et les usagers, Paris, Económica, 1991: OECD, Administration as Service: the Public as Client, Paris, OECD, 1982.

"J.R. GREENAWAY, Bureaucrats under pressure: the Thatcher Government and the Mandarin Elite, Teaching Politics, 13/1, 1984, págs. 66-84; Reflexiones para Mo. dernización de la Administracion, Madrid, 1989.

"- Rune Premfors, :The "Swedish Model" and Public Sector Reform, West European Politics, 14.3, 1991, págs. 88-9.

"Christopher HOOD, Reflections on the Variations in 1980's Public Management Reform, unpublished paper, LSE, december, 1991.

" OECD, Greece, Annual Repont, 1991-1992, Paris, OECD, 1992, pág. 59.

4: OECD, Portugal: Annual Report, 1988-1989, Paris, OECD, 1989, págs. 52-3.

* La Repubblica y Il Messagero, 16 de diciembre de 1993.

"Ver, por ejemplo, Miguel Beitrín VuLalBa, -La Administración pública y los funcionarios, en Salvador Ginés (ed.), España: sociedad y politica, Madrid, Espasa-Calpe, 1990 , págs. 342-8.

18 Jean Avastopoulos, Adapting the administration to the new economic situation: the case of Greece, Intermational Review of Administrative Sciences, Vol. 53, 1987, pág. 35-48.

19 Hans-Ulrich DERUEN, Historical legacy and recent developments in the German higher civil service, International Review of Administrative Sciences, Vol. 57, 1991, págs. 388-9; Klaus KÖNIG, •Administrative transformation: from a real-socialistic administration to a classical, European administration in Germany, articulo no publicado, IIAS Congeso Anual, Viena, 1992; Klaus GoETz, Rebuilding Public Administration in the New German Länder: a tale of differentiation, West European Politics, 16/4, octubre, 1993, págs. 447-64. 
* George Vervardanss y Catherine D. Papasthathopouros, The Higher Civil Service in Greece, Intermational Review of Administrative Sciences, Vol. 55, 1989, págs. 60329.

"Luc Roubav, La modemisation de l'État et la fin de la specificité française, Revrue Francaise de Sciences Politique, 40/4, agosto, 1990, págs. $521-45$.

$\because$ Walter J.M. KICKERT, Administrative Reform in British, Dutch and Danish Civil Services, arículo no publicado, 1993, págs. $9 \cdot 10$

"Premfors (nota 42), págs. 92-3.

i Ver, por ejemplo, U. ROSENTHAL y L.J. ROBORGH, Administrative Trends in the Netherlands, en MÉNY Y WRIGHT, (nota 32).

i Jorgen Gronnegard CHRISTENSEN, .Withdrawal of government: a critical survey of an administrative problem in its political context, International Review of Administrative Sciences, Vol. 54, 1988, pág. 58.

"Eduardo ZAPICO-GoNì, .la modernisation de l'administration publique espagnole: un éclatement des réformes, Revue Francaise d'Administration Publique, Vol. 66, abril-junio, 1993, pág. 314.5.

"Peter GeRuCH, Deregulation in Austria, European Joumal of Political Research, Vol. 17, 1989, págs. 209-22.

* B. Guy PETERS, Morale in the public service: a comparative enquiry, Intemational Review of Administrative Sciences, Vol. 57, 1991, págs. 421-40; Jean-Luc BODIGUEL, :Les Fonctonnaires en période de décroissance: moral, motivation et image., Politiques et Management Public, 6/7, 1989; Jean-Luc Bodiguel y Luc RouBan, Le Fonctionnaire détrôné, Paris, Presses de la FNSP, 1991; detalles de un articulo filtrado de la Permanent Secretary of Social Security (Secretaria Permanente de la Seguridad Social) en el Independent on Sunday, 20 de junio, 1993 y uno de Robin Bumler, del Head of the Civil Service (Director del Funcionariado, en el Independent, 21 de noviembre, 1993. Nicole DE MONIRICHER, - The career public service in France: problems and prospectso, International Review of Administrative Sciences, Vol. 57, 1991, págs. 373-84; detalles de un arículo filtrado del funcionariado superior francés en le Figaro, 14 de enero de 1993.

in Ver Peter Aucolv, •Administrative Reforming Public Management: Paradigms, Principles, Paradoxes and Pendulums, Governance, 3/2, abril, 1990, págs. 115-37.

"' Christopher HoOD, Public Administration: Lost an Empire, not yet found a role. en A. LEFTwICH, New Developments in Political Science, Aldershot, Gower, 1990.

"Aymé Frunçols, Evolution et processus de modernisation de la fonction publique en Belgique, arículo sin publicar, Congreso ILAS, Viena, 1992.

12. Este no es sólo el caso de Gran Bretana (donde las reformas de los años 70 ruvieron un impacto de corta vida). Ver, también, en los Países Bajos, U. Rosentrul y L.J. ROBORGH, AAdministrative Trends en los Paises Bajos, en MÉNY y WRIGHT (nota 32), pág. 25 (sobre el éxito limitado del primer gabinete de Lubber). Acerca del tema en general, ver; B. Guy PETERs, -Government Reorganisation: a theoretical analysis, Intemational Political Science Review, 13/2, 1992, págs. 199-217.

6: Christensen (nota 55), pág. 54; ZAPICO-Goñ (nota 56).

is Hanne Foss HAvSEN, Implementation of Modernisation. Paradoxes in the Public Control of Higher Educational Institutions- the case of Denmark, Scandinavian Political Studies, 13/1, 1990, págs. 37-56; Brian EDwARDS, The National Health Service: a Manager's Tale, Nuffields Provincial Hospitals Trust, 1993; P.M. JacksON, •Management Techniques in the UK Public Sector, Intermational Review of Administrative Sciences, Vol. 55, 1988, pág. 257.

tri Para diferenciar los distintos puntos de vista en el caso británico, ver Geoffrey $\mathrm{K}$. $F_{R Y}$. The Thatcher Govemment, the Financial Management Initiative and the "New Civil Service", Public Administration, Vol. 66, Primavera 1988, págs. 1-20; Richard A. Chapman, The Changing Administrative Culture of the British Civil Service en Colin CAMPBEL y B. Guy PETERS (eds.), Organising Governance, Governing Organisations, Pitnsburgh PA, University of Pinsburgh Press, 1988; James B. ChristoPh, The Remaking of British Administrative Culture, Administration and Society, 24.2, agosto 1992, págs. 163-81.

(1) Luc Rouban, The Civil Service and the Policy of Administrative Reform in France. International Review of Administrative Sciences, Vol, 55, 1989, págs. 445-65; Patrick GIBERT y Jean Claude THÓENG, .La gestion publique, Politiques el Management Public, marzo, 1992

"ì Ver, por ejemplo, Stefan KuHLmav, Informatization in Local Environmental Administration, en lgnace Th.N. SNELLEN et al. (ed.), Expent Systems in Public Administration, Amsterdam NY, Oxford, Elsevier Science Publications, 1989.

(s) F.F. RidLEY, Administrative Theory and Administrative Reform• en Gerald CAIDEN Strategies for Administrative Reform, New York, lexington Books, 1982, págs. 1-14; B. Guy PETERS, .Government Reorganization: a Theoretical Analysis, International Political Science Review, 13/2, 1992, págs. 199-217.

(f) Johan P. OLSEN, Administrative Reform and Theories of Organisation', en CAMPBEL y Peters (nota 65), págs. 233-54; B. Guy Peters, (nota 68).

$\therefore$ Para una breve exploración de este tema, ver P.C. PERRY y H.G. RanNEY, -The Public-Private Distinction in Organisational Theory, Academy of Management Review, n. ${ }^{n} 13,1988$, págs. 182-201. Para una exposición más larga, ver las obras de Peter SEIf, Government by the Market? The Politics of Public Choice, London, MacMillan Press, 1993. Ver también J. Chevalier y D. LosCHAK, Rationalité juridique et rationalité managériale dans l'administration française, Retre Française d'Administration Publique, n. 24, 1992, págs. 679-720.

$\because$ Kenneth KERVAGHAV, Introduction. en Social Change as a Source of Competing Va lues in Public Administration, Bruselas, IIAS, 1988, pág. 8. 